\title{
Contradições entre o ensino do SUS e a experiência no SUS: a ótica de estudantes de graduação em Enfermagem
}

\author{
Milleny Tosatti Aleixo, Ariana Colombari de Godoi Floresta, Erica Toledo de Mendonça, Erika
} Andrade e Silva, Deíse Moura de Oliveira

\begin{abstract}
Resumo
O Sistema Único de Saúde (SUS) representa um desenho inovador no cenário brasileiro, e está em permanente construção. Sua consolidação requer mudanças importantes, tanto nos âmbitos do serviço quanto do ensino, em busca de uma formação profissional que atenda às necessidades de saúde da população brasileira. A observação empírica evidencia dissonâncias entre o ensino e a realidade do SUS, sinalizando desafios nas esferas da formação e do serviço. Compreender as contradições entre o ensino do SUS e a experiência no SUS sob a perspectiva de estudantes de graduação em Enfermagem. Trata-se de um recorte de uma pesquisa mais ampla que estudou a interface entre o ensino de graduação e a formação voltada para o contexto do SUS sob a perspectiva de estudantes de graduação em Enfermagem. Tal pesquisa, de natureza qualitativa, teve como cenário o curso de Enfermagem da Universidade Federal de Viçosa (UFV). Participaram 11 estudantes que estavam no estágio curricular supervisionado, sendo a coleta de dados realizada nos meses de março a maio de 2015, através de um roteiro de entrevista com questões abertas. Os dados coletados foram analisados por meio da análise de conteúdo de Bardin e interpretados em consonância com a literatura pertinente à temática. O estudo foi aprovado pelo Comitê de Ética e Pesquisa com Seres Humanos da UFV, inscrito sob o Parecer n. 909.697. Os estudantes percebem o compromisso da instituição na qual estão inscritos com a proposta formadora para o SUS. Entretanto, revelaram a desarticulação entre o que lhes é ensinado e o que vivenciam no cotidiano do sistema. Entre os elementos que a deflagram, destaca-se o comodismo de alguns profissionais, a descrença dos mesmos em relação ao SUS e a dificuldade de construir na prática redes efetivas de atenção à saúde. Os discentes acreditam que tais nós críticos contribuem para que o funcionamento do sistema seja limitado e sua compreensão dificultada, em função da incongruência entre o SUS prescrito e o SUS real. Os estudantes também se referiram a conteúdos que não foram trabalhados a contento durante a graduação ou restringiram-se à abordagem teórica, insuficiente para prepará-los para a realidade do sistema. Denotaram a necessidade de mais vivências práticas e discussões, visto que esses momentos mobilizam os discentes e possibilitam reflexões necessárias para a atuação transformadora do enfermeiro no cenário da saúde no Brasil. O presente estudo, ao revelar contradições demarcadas na díade ensino-serviço, suscita reflexões e a necessidade de que estratégias sejam (re)pensadas para promover uma aproximação entre a formação e a realidade do sistema, viabilizando uma parceria que culmine na qualificação do SUS e, por conseguinte, do ensino neste contexto. Ressalta-se ainda a necessidade de redefinição constante da matriz curricular dos cursos de graduação em saúde e do desenvolvimento de investigações em outras realidades, ampliando as evidências científicas referentes ao SUS e à formação que atenda às necessidades emergentes do sistema de saúde brasileiro.
\end{abstract}

Descritores: Educação em Enfermagem; Sistema Único de Saúde; Pesquisa Qualitativa. 